\title{
A Study for Renewable Energy Generation and Sustainable Development in China
}

\author{
Qianyu Dong and Tohru Futawatari
}

\begin{abstract}
China is faced with significant challenges in the economic growth, energy consumption and environmental crisis, which severely restrict its sustainable development. Meanwhile the promotion of renewable energy is used to be regarded as the key solution to tackling those issues. However, it is not clear whether the $\mathrm{RE}$ generation really related with China's sustainable development or not. Therefore, in this paper, we elaborated the current status and trends of renewable energy generation in China both from the installed capacity and generation by sources. Then, based on a correlation analysis, we found the development of renewable energy generation has a greater correlation with GDP growth while less related with fossil fuel electricity consumption decrease and $\mathrm{CO}_{2}$ emissions reduction. Accordingly, we considered that to improve energy efficacy of fossil fuel power will be more helpful for China's sustainable development rather than promoting renewable energy generation in the short term. At last, some suggestions for China's renewable energy generation and sustainable development were presented.
\end{abstract}

Index Terms-Renewable energy, generation, GDP, $\mathrm{CO}_{2}$ emissions, sustainable development.

\section{INTRODUCTION}

China has been experiencing a significant contradiction among economic growth, energy consumption and environmental crisis in recent years. Under this circumstance, renewable energy (RE) as a kind of alternative energy which does not harm the environment and could meet the power demand has been placed high hopes for Chinese sustainable development.

$\mathrm{RE}$ is generally defined as energy that comes from resource which is naturally replenished on a human timescale. RE generation mainly includes hydropower, solar $(\mathrm{PV})$ power, wind power, biomass energy and geothermal energy. In the year of 2012, China's RE generation capacity has reached 1010TWh, which ranked the second of the world [1], and taken $20.2 \%$ of China's annual total electricity generations [2]. China's aspiring RE development has attracted increasing attentions, a mass of studies have conducted related studies, including conducting renewable case studies in a region or province [3]; analyzing the interactions between RE development and environment [4]; reviewing the barriers and opportunities of RE [5], [6]; circumstantiating the development situation for a certain kind

Manuscript received May 19, 2014; revised July 7, 2014.

Qianyu Dong is with the Faculty of Environmental Engineering, The University of Kitakyushu, Fukuoka, Japan (e-mail: author@boulder.nist.gov).

Tohru Futawatari was with the Faculty of Environmental Engineering, The University of Kitakyushu, Fukuoka, Japan (e-mail: author@lamar.colostate.edu). of RE in China. Although with so many studies focuses on a certain technology aspect of RE in China, few of them have systematic invested the progress of every kind of RE from the perspectives of both installed capacity and generation Moreover, rare researches discussed about that whether the advance of RE generation really correlated with the country's sustainable development as expected or not. As a result, this study aims to 1) analyze the reasons and problems for development of RE generation; 2) discuss the correlations of RE generation with sustainable development; 3) give recommendations for the future development of $\mathrm{RE}$ generation industry.

\section{Status Quo ANALysis of RE GENERATION IN ChinA}

\section{A. The Distribution of RE Plants}

In contrast to the fossil fuel plants, RE power plants are built in the resourceful areas since RE resource is not able to be transported. Fig. 1 presented the top 10 provinces with RE installed capacities in 2012. And these power plants are mostly centralized in central regions of China. Particularly, regions consume much electricity (such as northeast and east coastal areas) are lack of RE plants. For the high transmission losses and expensive power network, to transmit RE electricity to these higher electricity demand areas is not cost-effective. It means the power used in these places has to be generated by fossil fuels, and the role of RE electricity is limited.

\section{B. Installed Capacity and Electricity Production of RE}

Fig. 2 described the trends of installed capacity of RE by sources from 2000 to 2012. Table I listed the growth rate of installed capacity of renewables, respectively. Clearly, the hydropower has the whip hand of accumulative installed capacity, but compared with other renewables, its growth rate is the lowest. We consider the root reason should be that hydropower's growth is from a higher baseline. Additionally, for the heated controversy about the ecological influence of hydropower exploitation, China stopped the approval of new large-scale hydropower plants in 2009. Even then because of the heavy pressure of reducing $\mathrm{CO}_{2}$ emissions, they restarted the approval again in 2010, but the growth rate of newly installed capacity is much slower than before. And the new constructions are focused on small size hydropower stations.

In terms of wind power, as shown in Table I, which replaced hydropower to own the biggest newly installed capacity from 2010, and enjoyed the highest growth speed till 2009. We considered the reason should be to meet the rising power demands in northeast industrial areas and developed eastern coastal areas (where are plenty for wind resource as 
shown in Fig. 1). China turned to focus on enlarging the scale of wind power plants in these regions since 2000. And a plenty of market-oriented policies has been set out. For example, the concession bidding of wind power was implemented between 2003 and 2007. It aimed at promoting the competitive mechanism and a reasonable feed-in tariff of wind power, and urged the multiply increase in installed capacity of wind power.

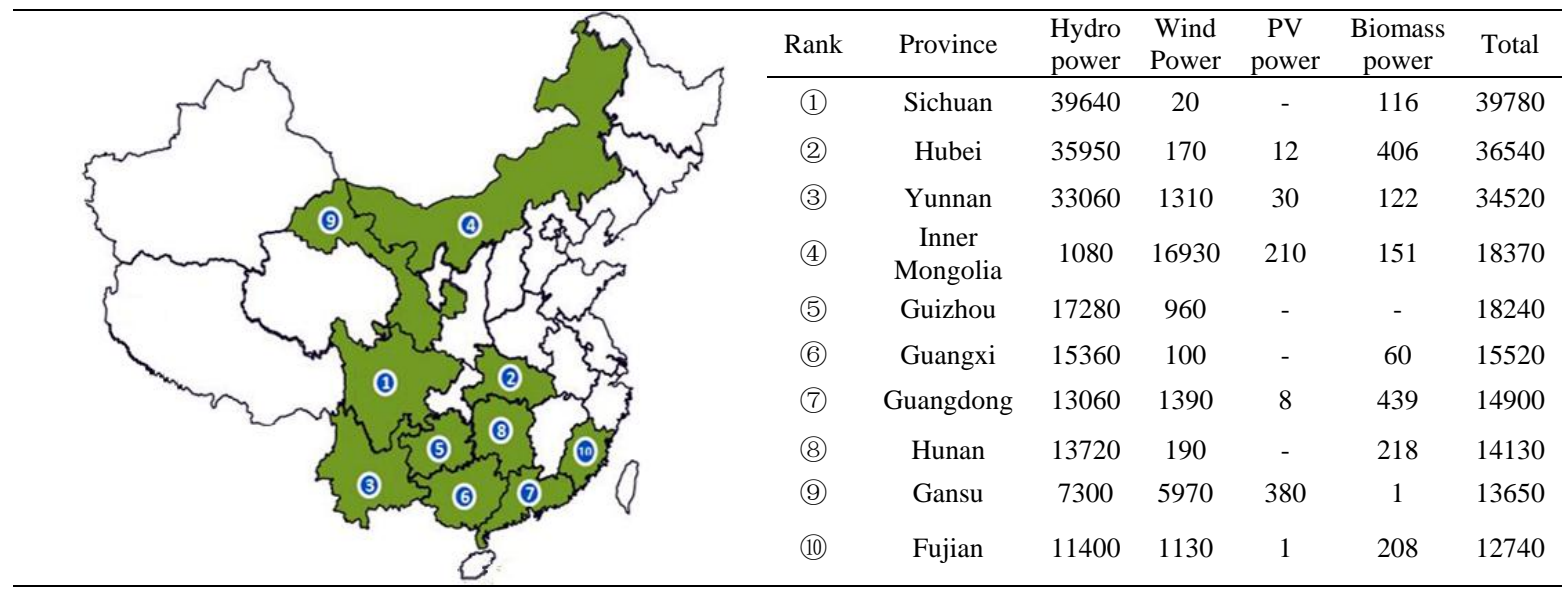

Fig. 1. The provinces with top 10 RE power installed capacity in 2012 (MW).

Source: 2012 China Renewable Energy Outline by China National Renewable Energy Center

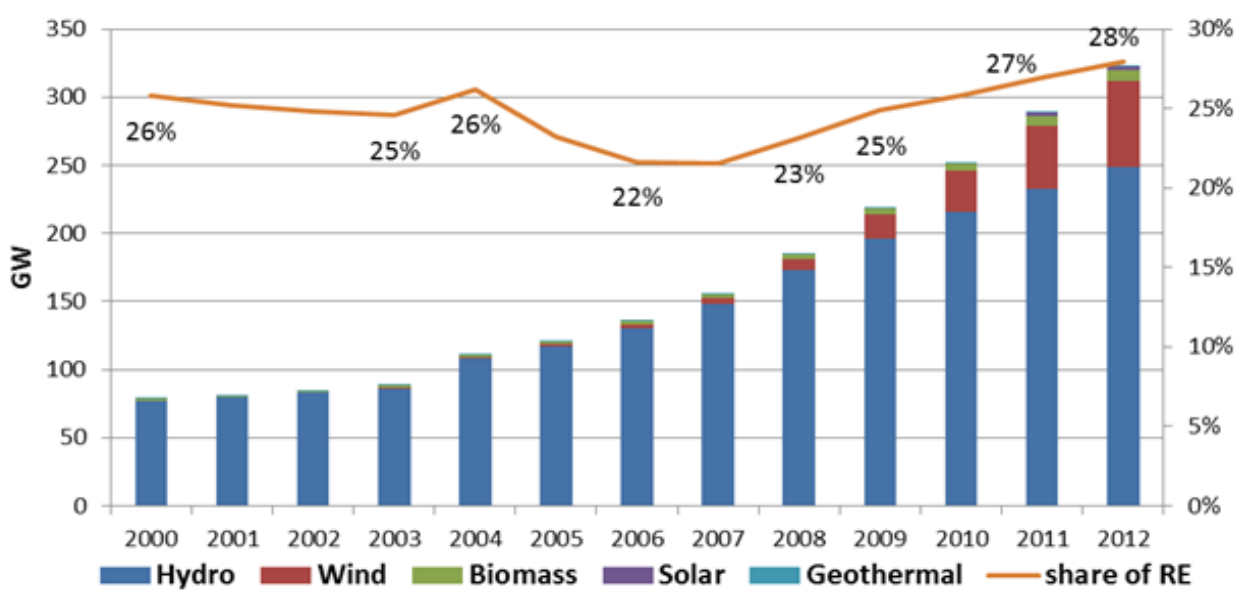

Fig. 2. Installed capacity of RE in China from 2000 to 2012(GW).

Source: 2012 China Renewable Energy Outline by China National Renewable Energy Center

TABLE I: GROWTH RATE OF INSTALLED CAPACITY OF RE IN CHINA

\begin{tabular}{lccccccccccccc}
\hline & 2001 & 2002 & 2003 & 2004 & 2005 & 2006 & 2007 & 2008 & 2009 & 2010 & 2011 & 2012 \\
\hline Hydro & $3.1 \%$ & $4.6 \%$ & $3.7 \%$ & $25.8 \%$ & $8.4 \%$ & $11.0 \%$ & $13.8 \%$ & $16.4 \%$ & $13.7 \%$ & $10.1 \%$ & $7.8 \%$ & $6.8 \%$ \\
Wind & $12.1 \%$ & $17.6 \%$ & $21.9 \%$ & $36.1 \%$ & $69.6 \%$ & $106.3 \%$ & $61.6 \%$ & $99.8 \%$ & $109.8 \%$ & $68.1 \%$ & $56.3 \%$ & $35.5 \%$ \\
PV & - & - & - & - & - & - & - & - & - & $766.7 \%$ & $753.5 \%$ & $47.8 \%$ \\
Biomass & $0.0 \%$ & $0.0 \%$ & $50.0 \%$ & $0.0 \%$ & $33.3 \%$ & $25.0 \%$ & $20.0 \%$ & $9.0 \%$ & $40.7 \%$ & $19.6 \%$ & $27.3 \%$ & $14.3 \%$ \\
\hline
\end{tabular}

From 2010, PV has displaced the wind power as the fastest growing RE (Table I). This amazing growth could be attributed to three reasons. Firstly, contrary to hydropower, PV's growth is from a pretty low baseline. Consequently, it is easier to achieve a high growth rate. Secondly, the development of PV installed capacity is mainly pushed by China's manufacturing industry of solar cell. Actually, since China has become the biggest PV cell producer of the world in 2007, its heavy dependency on oversea market has given rise to the appeal of expanding the domestic PV market. Meanwhile, the declining demands of oversea market also forced China to explore domestic market to solve excess capacity. Thirdly, the national PV support project such as 'Golden Sun' was launched from 2009 to 2013, which aimed to increase $500 \mathrm{MW}$ for PV installed capacity.

In the field of electricity production, Fig. 3 depicted annual proportion of RE in total power generation and renewables generation by sources from 2001 to 2012 , respectively. Table II tabulated the growth rate of RE generation during the same period. Similar as installed capacity, hydropower has the highest generation and lowest growth rate. And compared with other renewables, hydropower is more fluctuant for the instability of water resource, and which greatly affected the ratio of RE power in China's gross generation (Fig. 3). Wind power keeps a stable increase. PV power has most explosive growth, but its generation is insignificant for the low baseline. About $72 \%$ of PV power came from centralized PV stations [2]. This is different with PV power well developed 
countries, where distributed PV system is the mainstream. But for a distributed power market, it is imperative to break
China's electricity monopoly. That will be pretty difficult in a short time.

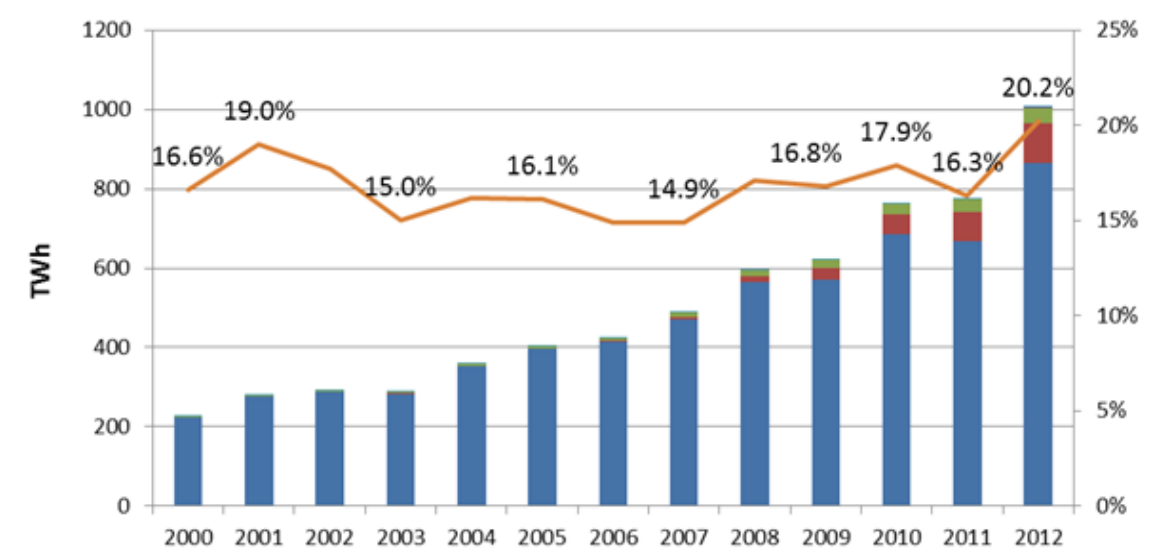

Hydro Wind Biomass - Solar Geothermal — Share of RE

Fig. 3. Electricity generation of RE in China from 2000 to2012 (TWh).

Source: 2012 China Renewable Energy Outline by China National Renewable Energy Center

TABLE II: GROWTH RATE OF RE GENERATION IN CHINA

\begin{tabular}{lcccccccccccc}
\hline & 2001 & 2002 & 2003 & 2004 & 2005 & 2006 & 2007 & 2008 & 2009 & 2010 & 2011 & 2012 \\
\hline Hydro & $24.7 \%$ & $3.8 \%$ & $-1.5 \%$ & $24.6 \%$ & $12.1 \%$ & $4.6 \%$ & $13.6 \%$ & $20.0 \%$ & $1.1 \%$ & $20.1 \%$ & $-2.7 \%$ & $29.3 \%$ \\
Wind & $12.1 \%$ & $17.6 \%$ & $21.9 \%$ & $36.1 \%$ & $69.6 \%$ & $106.3 \%$ & $125.3 \%$ & $129.8 \%$ & $110.8 \%$ & $78.9 \%$ & $50.0 \%$ & $36.0 \%$ \\
PV & - & - & - & - & - & - & - & - & - & - & $600.0 \%$ & $400.0 \%$ \\
Biomass & $0.0 \%$ & $0.0 \%$ & $50.0 \%$ & $0.0 \%$ & $57.6 \%$ & $34.6 \%$ & $39.1 \%$ & $51.1 \%$ & $40.7 \%$ & $19.6 \%$ & $27.3 \%$ & $20.6 \%$ \\
\hline
\end{tabular}

In sum, China's progress in RE generation is largely led by hydropower and wind power, and government plays an important role. Meanwhile the domestic market-driven mechanism is forming, and the links between RE generation and external conditions are stronger. But, electricity monopoly has blocked the further growth of RE generation.

\section{Problems for the Development of RE Generation}

As compared Fig. 2 with Fig. 3, we observed that the share of RE is close to one third of the total installed capacity, but the share of RE in gross generation is only one fifth. This problem might in part because RE is susceptible to weather condition. But, we considered that the comparison revealed the 'Blindly expand' of RE generation. It means that the installed capacity of RE is already considerably larger than the output capacity of power grid. Taking wind power as an example, we found a phenomenon called 'wind curtailment' has already happened in Inner Mongolia. The abandon rate of China's wind power was $17 \%$ in 2011 , that means more than $120 \mathrm{GW}$ of wind power was wasted [7]. The reasons could not only be the low utilization level, but also the unplanned exploration. If the grid is not capable enough to accept the increase of RE electricity in a time, instead of accelerating the installed capacity, they should focus on update the grid and related management systems.

\section{CoRrelation ANALYSIS OF RE GENERATION AND SuSTAINABLE DEVELOPMENT IN CHINA}

On account of the limited data about RE generation in China, we collected yearly data from 2000 to 2012 as the sample. The data mainly come from China National Renewable Energy Center (CNREC), the U.S. Energy Information Administration (EIA), International Energy Agency (IEA), China Energy Statistics Yearbook, World Development Indicators (WDI) and the World Bank Datebook and so on.

TABLE III: CORRELATION BETWEEN RE ELECTRICITY AND $\mathrm{CO}_{2}$ EMISSIONS REDUCTION

\begin{tabular}{lccc}
\hline & \multicolumn{2}{c}{ RE generation } & $\begin{array}{c}\text { Ratio of RE in total } \\
\text { generation }\end{array}$ \\
\hline $\mathrm{CO}_{2}$ from fossil & $r$ & $0.929 * *$ & $0.438^{* *}$ \\
fuel electricity & Sig.(2-tailed) & 0.001 & 0.570 \\
\hline
\end{tabular}

TABLE IV: RE ELECTRICITY AND FOSSIL FUELS ELECTRICITY

\begin{tabular}{|c|c|c|c|}
\hline \multicolumn{4}{|c|}{ Fossil fuel electricity } \\
\hline \multirow{2}{*}{\multicolumn{2}{|c|}{ RE electricity }} & & $.989^{* *}$ \\
\hline & & led) & .000 \\
\hline \multicolumn{4}{|c|}{ Growth rate of fossil fuel electricity } \\
\hline \multirow{2}{*}{\multicolumn{2}{|c|}{$\begin{array}{l}\text { Growth rate of RE } \\
\text { generation }\end{array}$}} & & $-.604^{* *}$ \\
\hline & & led) & .029 \\
\hline \multicolumn{4}{|c|}{ TABLE V: RE ELECTRICITY AND $\mathrm{CO}_{2}$ GDP } \\
\hline \multicolumn{3}{|c|}{ GDP } & GDP growth \\
\hline \multirow[b]{2}{*}{ RE generation } & $r_{s}$ & $-0.667 *$ & $0.438^{* *}$ \\
\hline & Sig.(2-tailed) & 0.071 & 0.570 \\
\hline
\end{tabular}

Without doubt, the national energy system is complicated 
and interlocking. However, to some extent, the correlations among the indicators and phenomenon are not hard to find. Hence, in this paper, we would like to focus on exploring the reasons behind the links, and find realistic solutions for the future development.

We adopt Spearman's rank-order correlation to assess how well the relationship can be described by a correlation coefficient $\left(r_{s}\right)$. Spearman's rank correlation coefficient $\left(r_{s}\right)$ always gives an answer between -1 and 1 . The numbers are like a scale, where -1 is a negative correlation, 0 is no link, and 1 is a positive correlation. And closer $\left|r_{s}\right|$ is to 1 , stronger is the correlation. The p-value is a measure of the probability of obtaining a result at least as extreme as the one that is actually observed, so the lower the value (usually below 0.05 or 0.01) the more significant the result [9].

\section{A. RE Electricity and $\mathrm{CO}_{2}$ Emissions Reduction}

Based on correlation coefficient $\left(r_{s}\right)$ in Table III, it indicated the RE generation is strongly positive correlated with $\mathrm{CO}_{2}$ emissions from generation $\left(r_{s}>0.9\right.$, p-value $<$ $0.05)$, this result revealed that $\mathrm{CO}_{2}$ emissions increase while the RE generation grows, which also suggesting that the development of RE generation does not significant correlated with $\mathrm{CO}_{2}$ emissions reduction. Moreover, Table III also demonstrated that the ratio of $\mathrm{RE}$ in gross generation is uncorrelated with $\mathrm{CO}_{2}$ emissions from electricity production. This suggesting that, no matter the proportion of RE increase or decrease, there is no certain change to the $\mathrm{CO}_{2}$ emissions from electricity production. In other words, even the proportion of $\mathrm{RE}$ in total power generation increase, but the proportion of $\mathrm{CO}_{2}$ emissions from electricity production might not decrease.

\section{B. RE Electricity and Fossil Fuels Electricity}

As shown in Table IV, RE electricity and fossil fuel electricity are strongly positively correlated, the growth rate of RE and fossil fuel electricity is significant negatively correlated $\left(r_{s}<0\right.$, p-value $\left.<0.05\right)$, suggesting that as the RE generation accelerated, the growth rate of fossil fuel electricity decreased.

\section{4.3 RE Generation and Economic Growth}

Based on Table V, RE generation is significantly positive correlated with GDP $\left(r_{s}>0.9, p<0.01\right)$, suggesting that as $\mathrm{RE}$ generations increase, GDP grows as well. While RE generation is uncorrelated with real GDP growth rate.

In brief, RE generation has a greater correlation with GDP growth while less related with fossil fuel electricity consumption decrease and $\mathrm{CO}_{2}$ emissions reduction.

\section{DISCUSSION}

China is on the developing period of industrialization, and its economic growth is driven by large scale production. But the scale economy not only comes with large sum of energy consumption but also the by-product of environmental damage. And RE is always regarded as the key to address this dilemma. However, in this study, we found that RE generation has a greater correlation with GDP growth while less related with fossil fuel electricity consumption decrease and $\mathrm{CO}_{2}$ emissions reduction. We discussed it as follows.

Firstly, the enormous investment on RE is an important driving force of China's GDP. China's investment at RE has reached 66.6 billion dollars in 2012 [8], which occupied $0.81 \%$ of GDP. The huge investment not only greatly promoted RE generation, but also stimulated related industries (such as the raw material supply and manufacturing industries of RE plants, the technology companies). For another perspective, just like we discussed previously in Section II, the over fast growth of RE installed capacity might be used as a way to boost economic growth of China. Besides, in order to achieve the target of 'RE accounts for $30 \%$ of total installed capacity in 2020 ' set by National Development and Reform Commission, we believe the installed capacity of RE will keep growing. But, the gap between RE installed capacity and generation should be attached more importance. After all, the electricity production by RE is more essential than inapplicable huge installed capacity.

Secondly, the ever-increasing power demand has improved the growth of both RE electricity and fossil fuels electricity, but RE electricity is hard to challenge the fossil fuel electricity in a short term. Since fossil fuel electricity has dominated China's energy system for decades. And RE generation is easy to be affected by weather conditions generation (especially hydropower), meanwhile the fossil fuel electricity could be transported and change with the insufficient anytime. Moreover, the cost of coal power is much cheaper than RE generation, and which is hard to be changed in a short period. Thus, RE's effect on reducing fossil fuels electricity will not be effective.

Thirdly, the $\mathrm{CO}_{2}$ emission is positively correlated with the fossil fuel electricity consumption. China's RE generation has experienced a rapid expansion since 2000, but that is from a lower baseline. Meanwhile the fossil fuels electricity climbs up as well by a faster speed and greater capacity than the RE electricity. Consequently, even though RE consumption and generation keeps fast growing, but this growth in RE generation was more than offset by a $6.4 \%$ increase in coal consumption [1]. For which has a higher baseline while most of $\mathrm{CO}_{2}$ emission is attributed to the low-efficient coal power plants. Moreover, the fluctuating growth rate of $\mathrm{RE}$ generation leads to a floating ratio of $\mathrm{RE}$ generation in gross electricity generation. So, although a new peak of RE generation got in 2012, but its share is not stable and big enough to contend with coal power. Thus, to reduce $\mathrm{CO}_{2}$ emissions in China, the more important should be increasing energy efficiency.

Based on the problems we explored, some recommendations are given as follows: Firstly, China should focus on increasing energy efficiency of coal power. Because of bigger base number, the efficiency of thermal power plants will be more significant on $\mathrm{CO}_{2}$ emissions reduction. Secondly, enlarging transmission capacity prior to explore installed capacity of RE. If only with a huge installed capacity, but a laggard power transmission system, it means more RE generation will be wasted. Thirdly, complete the policy planning and decision making mechanism. Fourthly, expanding the concession bidding system in all kinds of RE generation industry. Because this system is proved by wind 
power department that which could act as a buffer between competitive mechanism and policy-oriented industry. Fifthly, open up the distributed RE power market and to break the electricity monopoly. In addition, a comprehensive and objective understanding about the influence of hydropower should be conducted both for the public and policy makers. Lastly, the loss in GDP for decelerating new construction of $\mathrm{RE}$ could be shifted to the promotion of power system and energy efficiency. So, even the growth in installed capacity of RE is slow down, but the influence on economy can be minimized.

\section{CONCLUSION}

At present, RE generation is hard to drive a fundamental transition in China's energy system because its limited effects on $\mathrm{CO}_{2}$ emissions reduction and fossil fuel electricity decrease. If China expect to expand the RE's influence, it will require sharply limiting the use of fossil fuels on which more than 80 percent of today's Chinese energy system depends. And that, in turn, would set off a sweeping transition of one of the most extensive, technologically complex, and deeply embedded elements of China's physical infrastructure: the national energy system, economic growth and industrial structure. But these transformations are incredibly difficult to be finished in a decade. Therefore, China will necessarily continue to rely on fossil fuels in the coming decades. And during this period, compared with a bigger ratio of $\mathrm{RE}$ in generation, to raise the energy efficiency of fossil fuels is more useful and practical for China's sustainable development.

\section{REFERENCES}

[1] Trends in Global $\mathrm{CO}_{2}$ Emissions 2013 Report, PBL Netherlands Environmental Assessment.

[2] China Renewables and Non-Fossil Energy Utilization, Beijing: China National Renewable Energy Centre (CNREC), China, 2013.
[3] L. Hong, H. Lund, B. V. Mathiesen, and B. Möller, "2050 path way to an active renewable energy scenario for Jiangsu province," Energy Policy, pp. 267-278, 2013.

[4] T. Liu, G. Xu, P. Cai, L. Tian, and Q. Huang, "Development forecast of renewable energy power generation in China and its influence on the GHG control strategy of the country," Renewable Energy, pp. 1284-1292, 2011.

[5] Q. Wang and Y. Chen, "Barriers and opportunities of using the clean development mechanism to advance renewable energy development in China," Renewable Sustainable Energy Reviews, pp. 1989, 2010.

[6] H. Y. Ma, L. Oxley, and J. Gibson et al., "A survey of China's renewable energy economy," Renewable and Sustainable Energy Reviews, pp. 438-445, 2010.

[7] The State Electricity Regulatory Commission (SERC), Research Report on the Wind Power Development in China, Beijing, China, 2012.

[8] China National Renewable Energy Center (CNREC), 2012 China Renewable Energy Outline, Beijing, China, 2014.

[9] A. Field, Discovering Statistics Using SPSS, 3rd ed. London: Sage Publications, England, 2010.

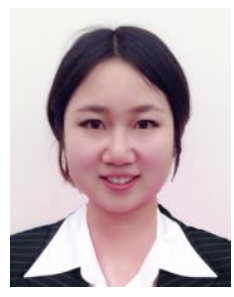

Qianyu Dong received the B.S. degree in marketing from the Southwest Petroleum University, Chengdu, China in 2008, the M.S. degree in management science and engineering from the Southwes Petroleum University in 2011. She is currently working toward the Ph.D. degree at the University of Kitakyushu, Japan. Her research interests include environmental management, environmental management system, public environmental awareness, consumer purchase behavior and psychology.

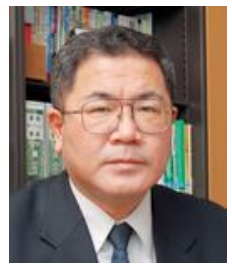

Tohru Futawatari received M.S. degree from the School of Engineering, Kyushu University 1984, and D.E. degree from Kyushu University in 1993. He had been a research associate in University of Kitakyushu from 1984 to 1995.

Then, he moved to the University of Occupational and Environmental Health, to be an associate professor from 1995 to 2004 . Then, he moved to the University of Kitakyushu, and is a professor in the Faculty of Environmental Engineering and Graduate School of Environmental Engineering since 2003. His research interests are mainly focus on regional environmental management, environmental management system, environmental accounting, reporting and labeling, environmental risk and risk management, environmental management for social sector and NGO/NPO, corporate social responsibility. 